\title{
Behaviour of normal reinforced concrete columns exposed to different soils
}

\author{
Laith Rasheed ${ }^{1, *}$, Shakir Salih $^{2}$, Zahraa Hanash $^{1}$ \\ ${ }^{1}$ College of Engineering, University of Kerbala, Kerbala, Iraq \\ ${ }^{2}$ Building and Construction Engineering Department, University of Technology, Bagdad, Iraq
}

\begin{abstract}
Concrete resistance to sulfate attack is one of the most important characteristics for maintaining the durability of concrete. In this study, the effect of the attack of sulfate salts on normal reinforced concrete column was investigated by burying these columns in two types of soils (sandy and clayey) in two pits at a depth of $3 \mathrm{~m}$ in one of the agricultural areas in the holy city of Karbala, one containing sandy soil ( $\mathrm{SO} 3=$ $10.609 \%$ ) and the other containing clayey soil with $(\mathrm{SO} 3=2.61 \%)$. The tests were used (pure axial compression test of reinforced concrete columns, compressive strength test, and splitting tensile strength test, absorption, voids ratio and finally density). It's found that the strength of RC columns decreasing by (12.51\%) for age (240 days), for columns buried in clayey soil, where the strength increased by (11.71\%) for the same period, for columns buried in sandy soils, with respect to the reference column.
\end{abstract}

\section{Introduction}

Sulfate ions are found in groundwater and soil in southern parts of Iraq. Concrete structures in the regions of this part subjected to attack from sulfates may suffer from two types of damage; loss of strength of the matrix due to degradation of calcium-silicate-hydrate (C-S-H), and volumetric expansion due to formation of gypsum or ettringite that leads to cracking [1]. Protecting against sulfate attack requires reducing the permeability of concrete, whereby low permeability characteristics of concrete can prolong the service life of a structure that is subjected to severe exposure conditions [2]. The present study includes an attempt to produce reinforced concrete mix that can stand up against sulfate attack investigating, Normal reinforced concrete was used to study the strength and durability performance of this type of concrete. The main aim of the present work is to evaluate the effect of sulfate salts in groundwater and soil on strength and durability characteristics of normal reinforced concrete columns under pure axial compression force. Through this investigation (7) reinforced concrete columns are tested, where a (42) cubes are performed to cover a compressive strength, absorption, density, and voids tests. Splitting tensile strength are undertaken on (21) cylinders. The specimens are buried in sandy and clayey soils, for up to (240) days, in aggressive solution containing $\left(\mathrm{Cl}^{-}+\mathrm{SO}_{4}{ }^{-}\right)$at

* Corresponding author: 1aith.alqarawee@gmail.com concentration identical to those present in soil and groundwater in the southern parts of Iraq.

\section{Experimental work}

\subsection{Experimental program}

All groups of columns, were identical in size, (150x150) $\mathrm{mm}$ square section and overall height $(1080 \mathrm{~mm})$. They were casted in a vertical direction and hardened in fresh water conditions until 28-days. After that, they were buried and hardened in soils with different concentrations of sulfate and chloride solutions for a period of 60,150 , and 240 days. Then, all groups of columns were tested under axial static load by mechanical machine with electrical seal load in period 60, 150, and 240 days as shown in Figure 1 and mechanical and electronic dial gauges. The capacity of machine was $(1000 \mathrm{kN})$, it had a rigid structure frame, and the capacity of mechanical gauges $(2 \mathrm{~cm})$ and $(5 \mathrm{~cm})$ for electronic dial gaugeTest started with the application of $7 \mathrm{kN} / \mathrm{m}^{2}$ load to set and check dial gauge. Then initial reading of dial gauges is obtained. The load was applied in stages. At each load increment, observations of crack development on the concrete columns traced. Also, at each test, the first visible cracking load and reading of dial gauges were recorded. The process of reading the gauges and crack observations took about five to ten minutes. Once this process got completed, loading 
resumed to the next load step. The same procedure was followed. The load was continued until ultimate load that recorded. All columns were divided into two groups, one buried in clayey soils and other buried in sandy soil, the main details of the mix used throughout this investigation in Table 1. The columns have the same amount of longitudinal reinforcement of $4 \varnothing 8 \mathrm{~mm}$ and stirrups of $7 \varnothing 6 \mathrm{~mm} / \mathrm{m}\left(\mathrm{A}_{\mathrm{s}}=0.00893 \mathrm{~A}_{\mathrm{g}}\right)$, as shown in Figure 1, which is less than the smallest percentage allowed in the ACI code by (0.0011) to observe the effect of sulfates.

Table 1. The main details of the mixes used throughout this investigation.

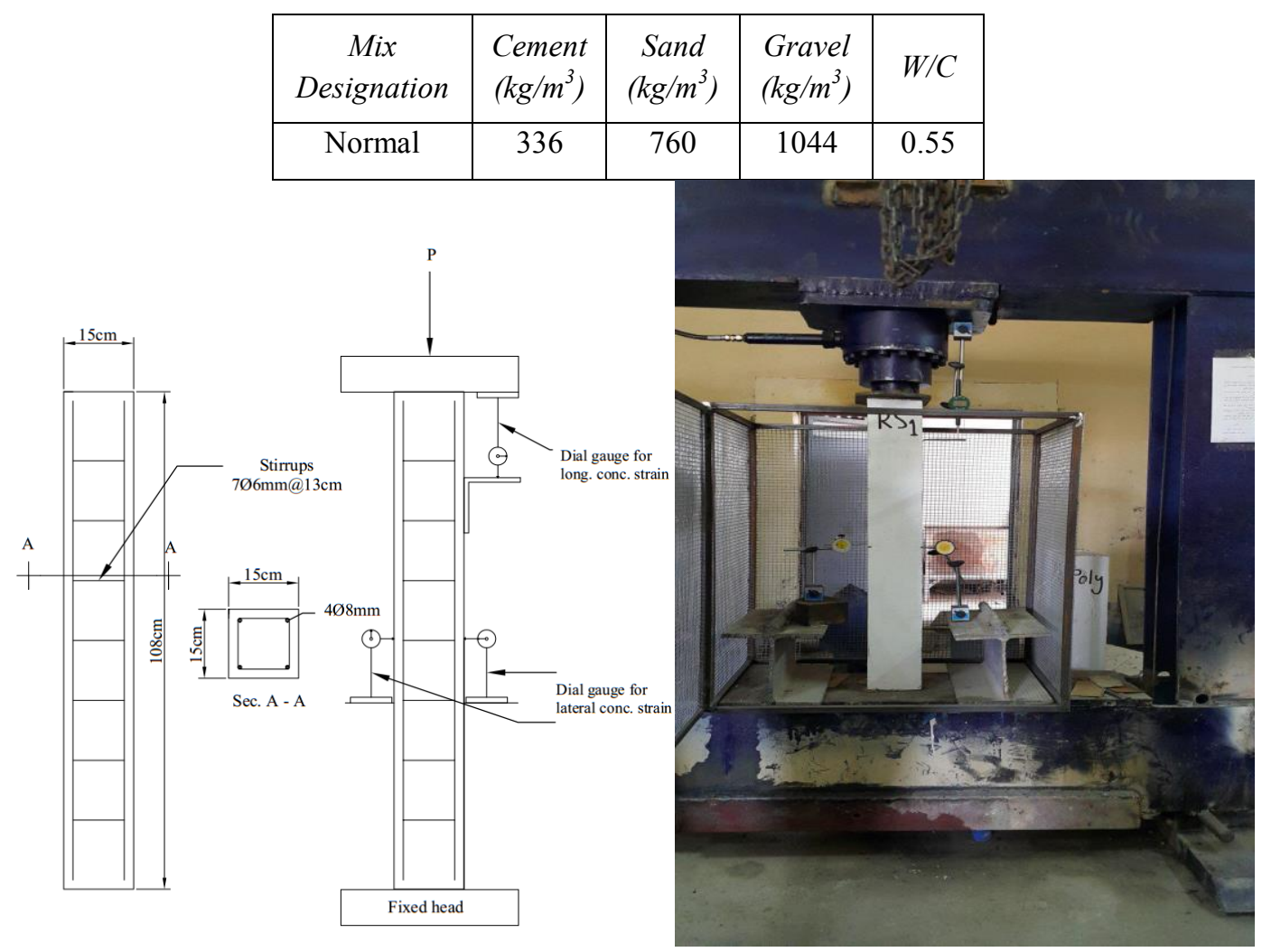

Fig. 1. Details of RC. tested columns and method of measuring their deformations.

\subsection{Materials}

In this research Portland Sulfate Resist Cement (ASTMType V) [3] manufactured by United Cement Company commercially known (AL-GESR) was used. The adopted cement confirms to the Iraqi Specifications No.5/1984 [4]. The fine aggregate from Al-Ekadir region was used throughout this work, it was within the requirements of (IQS No.45/ 1984) [5]. Black crushed stones of $20 \mathrm{~mm}$ maximum size from Al-Nebai quarry

\subsection{Soils}

Two types of soil were used to bury the specimens and RC columns models in clayey soil and sandy soil. Two pits were excavated in an agricultural land located to a location $(1.5 \mathrm{~km})$ west of Karbala centre. The pit's were used as a coarse aggregate in all mixes. which confirms to the Iraqi specification (IQS No.45/ 1984) [5]. The water used in the mix design was potable water from the water-supply network system; so, it was free from suspended solids and organic materials, which might have affected the properties of the fresh and hardened concrete. Deformed steel bars (8 and 6) $\mathrm{mm}$ diameter were used as reinforcement to test column specimens obtained from Turkish production. The steel reinforcement was tested according to ASTM-A615/A$615 \mathrm{M}-05 \mathrm{a}$.

dimension was $(2 \times 2 \times 3) \mathrm{m}$. The reinforced concrete columns models and their attached specimens were buried in the pits, then one pit was filled with the sandy soil, while the other pit was filled with the clayey soil, see Table 2. The ground water at August appeared in the pits in level $1.75 \mathrm{~m}$, which had the properties shown in the Table 3. 
Table 2. Physical and chemical properties for clayey and sandy soils.

\begin{tabular}{|c|c|c|c|c|c|c|c|c|c|c|c|c|}
\hline $\begin{array}{c}\text { Soil } \\
\text { Type }\end{array}$ & $\begin{array}{c}\mathrm{SiO}_{2} \\
\%\end{array}$ & $\begin{array}{c}\mathrm{Fe}_{2} \mathrm{O}_{3} \\
\%\end{array}$ & $\begin{array}{c}\mathrm{Al}_{2} \mathrm{O}_{3} \\
\%\end{array}$ & $\begin{array}{c}\mathrm{CaO} \\
\%\end{array}$ & $\begin{array}{c}\mathrm{MgO} \\
\%\end{array}$ & $\begin{array}{c}\mathrm{SO}_{3}{ }^{2} \\
\%\end{array}$ & $\begin{array}{c}\mathrm{Na}_{2} \mathrm{O} \\
\%\end{array}$ & $\begin{array}{c}\mathrm{K}_{2} \mathrm{O} \\
\%\end{array}$ & $\mathrm{Cl}^{-} \%$ & $\begin{array}{c}\mathrm{O} . \mathrm{M} \\
\%\end{array}$ & $\mathrm{PH}$ & $\mathrm{GS}$ \\
\hline Sandy & 18.31 & 2.95 & 4.55 & 26.86 & 5.87 & 10.60 & 4.24 & 0.64 & 1.95 & 0.62 & 8.15 & 2.6 \\
\hline Clayey & 33.79 & 6.40 & 12.43 & 12.49 & 7.79 & 2.61 & 2.20 & 1.35 & 0.78 & 0.83 & 8.3 & 2.5 \\
\hline
\end{tabular}

Table 3. Chemical properties for ground water

\begin{tabular}{|c|c|}
\hline $\mathrm{SO}_{4}{ }^{-} \mathrm{ppm}$ & 4675.5 \\
\hline $\mathrm{Cl}^{-} \mathrm{ppm}$ & 11182.5 \\
\hline $\mathrm{PH}$ & 8.45 \\
\hline
\end{tabular}

\section{Results and discussion}

\subsection{Results of hardened concrete properties}

The compressive strength of specimens decreased in clayey soil with time and increased in sandy soil. The tensile strength of concrete cylinders showed that it has increased over time, this may be due to the salt affected to improve bonds between the concrete particles. The absorption has decreased with time, the maximum increment in the absorption was recorded in cubes buried in the sandy soil for (240 days) by $5.09 \%$, and in cubes buried in the clayey soil by $9.83 \%$ for (240 days) compared with the reference cubes. It was also noted that the percentage of voids in the cubes had also decreased with time in all concrete mixes, specifically in the polymer mix, where the increase was $4.57 \%$ in cubes buried in sandy soil and $7.79 \%$ in cubes buried in the clayey soil for (240 days). A decrease in the percentage of voids and the absorption ratio in the normal mix was observed. This is due to the crystallization in the normal mix because of the presence of salts, which led to the closure of pores and reduced the percentage of voids and absorption in this mix and it was expected over time that the crystallization would increase the stresses in concrete, thus increase absorption rate and voids again Table 6 provides a summary of cubes and cylinders tests such as compression strength, tensile strength, absorption, voids ratio and density.

Table 4. Percentage of sulfates and chlorides in clayey and sandy soil over time.

\begin{tabular}{|c|c|c|c|c|c|}
\hline \multirow{2}{*}{ Soil Type } & Salt (\%) & \multicolumn{4}{|c|}{ Time of buried (days) } \\
\cline { 3 - 6 } & & 0 & 60 & 150 & 240 \\
\hline \multirow{3}{*}{ Clayey } & Sulfate $\left(\mathrm{SO}^{-}\right)$ & 2.61 & 4.41 & 3.50 & 3.04 \\
\cline { 2 - 6 } & Chloride $\left(\mathrm{Cl}^{-}\right)$ & 0.78 & 0.78 & 1.99 & 0.78 \\
\hline \multirow{2}{*}{ Sandy } & Sulfate $\left(\mathrm{SO}^{-}\right)$ & 10.6 & 9.5 & 9.0 & 9.6 \\
\cline { 2 - 6 } & Chloride $\left(\mathrm{Cl}^{-}\right)$ & 1.95 & 1.95 & 1.24 & 1.07 \\
\hline
\end{tabular}

Table 5. Results of the Experimentally Tested Columns

\begin{tabular}{|c|c|c|c|c|c|c|c|}
\hline $\begin{array}{l}\text { Group } \\
\text { Name }\end{array}$ & $\begin{array}{l}\text { Soil } \\
\text { Type }\end{array}$ & $\begin{array}{c}\text { Designation } \\
\text { Name }\end{array}$ & $\begin{array}{c}\text { Time of } \\
\text { Test } \\
\text { (days) }\end{array}$ & $\begin{array}{l}\text { Cracking } \\
\text { Load } \\
(P c),(k N)\end{array}$ & $\begin{array}{c}\text { Failure } \\
\text { Load } \\
(P u),(k N)\end{array}$ & $\begin{array}{l}\text { Long. } \\
\text { Def. } \\
(\mathrm{mm})\end{array}$ & $\begin{array}{c}\text { Lateral. } \\
\text { Def. } \\
\text { (mm) }\end{array}$ \\
\hline \multirow{4}{*}{$\mathrm{Nc}$} & Ref. & RS1 & 28 & 142.92 & 495 & 4.8 & 0.61 \\
\hline & \multirow{3}{*}{ Clayey } & $\mathrm{N} 2$ & 60 & 327.24 & 490.32 & 3.45 & 1.63 \\
\hline & & N3 & 150 & 440.23 & 509.76 & 4.79 & 0.525 \\
\hline & & N4 & 240 & 254.16 & 433.08 & 3.75 & 0.98 \\
\hline \multirow{3}{*}{ Ns } & \multirow{3}{*}{ Sandy } & NS2 & 60 & 158.4 & 439.2 & 7.43 & 1.56 \\
\hline & & NS3 & 150 & 111.24 & 529.56 & 5.23 & 0.74 \\
\hline & & NS4 & 240 & 552.96 & 552.96 & 3.25 & 1.28 \\
\hline
\end{tabular}


Table 6. Results of the Experimentally Tested Cubes and Cylinders.

\begin{tabular}{|c|c|c|c|c|c|c|c|}
\hline $\begin{array}{c}\text { Group } \\
\text { Name }\end{array}$ & Soil Type & $\begin{array}{c}\text { Time of } \\
\text { Test } \\
(\text { days })\end{array}$ & $\begin{array}{c}\text { Comp. } \\
\text { Strength } \\
\text { (Cube), } \\
(\text { MPa) }\end{array}$ & $\begin{array}{c}\text { Tensile } \\
\text { Strength } \\
\text { (Cylinder) } \\
(\text { MPa) }\end{array}$ & $\begin{array}{c}\text { Absorption } \\
\%\end{array}$ & $\begin{array}{c}\text { Voids } \\
\%\end{array}$ & $\begin{array}{c}\text { Density } \\
\text { Mg/m }\end{array}$ \\
\hline \multirow{2}{*}{ Nc } & Ref. & 28 & 27.75 & 2.712 & 5.2061 & 11.566 & 2.3457 \\
\cline { 2 - 8 } & Clayey & 60 & 27.365 & 2.034 & 3.1967 & 7.3703 & 2.383 \\
\cline { 3 - 8 } & & 150 & 26.723 & 3.3502 & 4.6073 & 9.7224 & 2.2076 \\
\cline { 3 - 8 } & 240 & 24.48 & 3.3815 & 4.6942 & 10.665 & 2.3755 \\
\hline \multirow{2}{*}{ Ns } & \multirow{2}{*}{ Sandy } & 60 & 27.767 & 2.0865 & 3.3125 & 7.5891 & 2.3665 \\
\cline { 3 - 8 } & & 150 & 27.013 & 2.7194 & 4.3789 & 9.3165 & 2.2212 \\
\cline { 3 - 8 } & & 240 & 29.75 & 3.9142 & 4.9412 & 11.037 & 2.3435 \\
\hline
\end{tabular}

\subsection{Effect of aggressive solution of clayey soil}

To understand the effect of sulfate and chloride on normal reinforced concrete columns, specimens buried for 60,150 , and 240 days in clayey soil to investigate its behavior. First visible crack was observed in the Normal Reinforced concrete columns group (Nc) at top and bottom of these columns at applied load of (142.92, $327.32,440.32$, and 254.16) $\mathrm{kN}$ for columns (RS1, N2, N3, and N4) respectively, as shown in Figure 2. The cracks propagated and grew, through the load progressing. At the final stages of loading the columns reached ultimate loads at $(495,490.32,509.76$, and 433.08) $\mathrm{kN}$ for columns (RS1, N2, N3, andN4) respectively. The failure occurred gradually with increased loads in the developed ages while the longitudinal deflection decreased, thus decrease in the area under the curve of load - deformation, which led to the columns became less tough and ductile with time, Figure 3 shows that the deflection was decreased with increasing buried time for the columns tested under the same loading, which means decreasing the ductility and toughness. As seen in the Figure 4 the lateral deflection increased over time at the same load for example (400 $\mathrm{kN}$ ), these increments were the reflection of the decrements in the longitudinal direction. From Table 5, it can be seen that, the ultimate load lightly enhanced until 150 days of buried time, while the harmful effected of sulfate and chloride was seen after this time, where the cracking load, and failure load of N2, N3 and N4 with respect to RS1 were $(229,308$, and $171 \%)$, and $(99,103$ and $87 \%$ ) respectively.

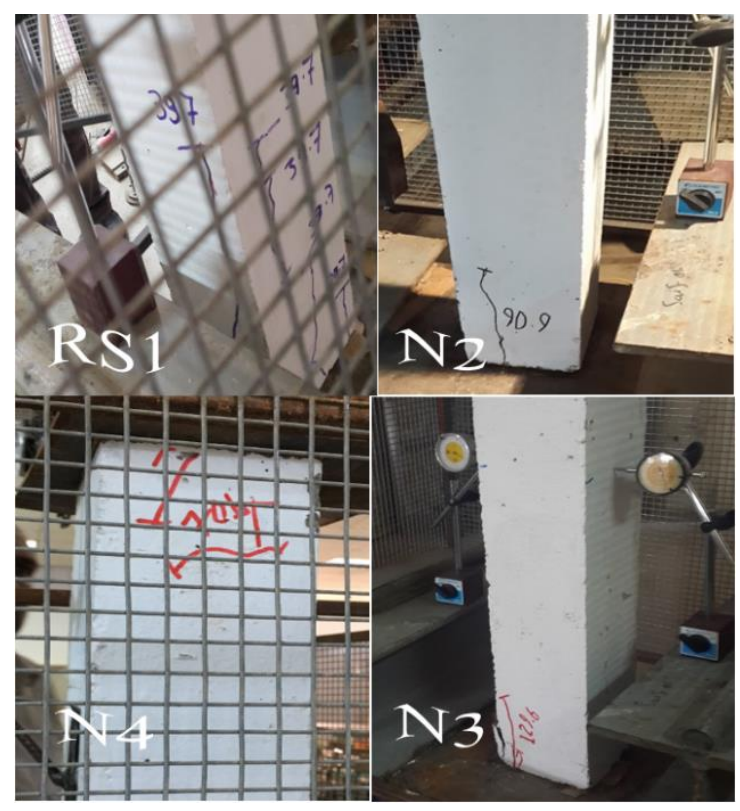

Fig. 2. First cracks for group (Nc) $(*$ the load factored by 3.6)

A possible reason for this increment in the lateral and longitudinal deflection is the effect of the sulfate and chloride in clayey soil on the strength of columns during the buried time. 


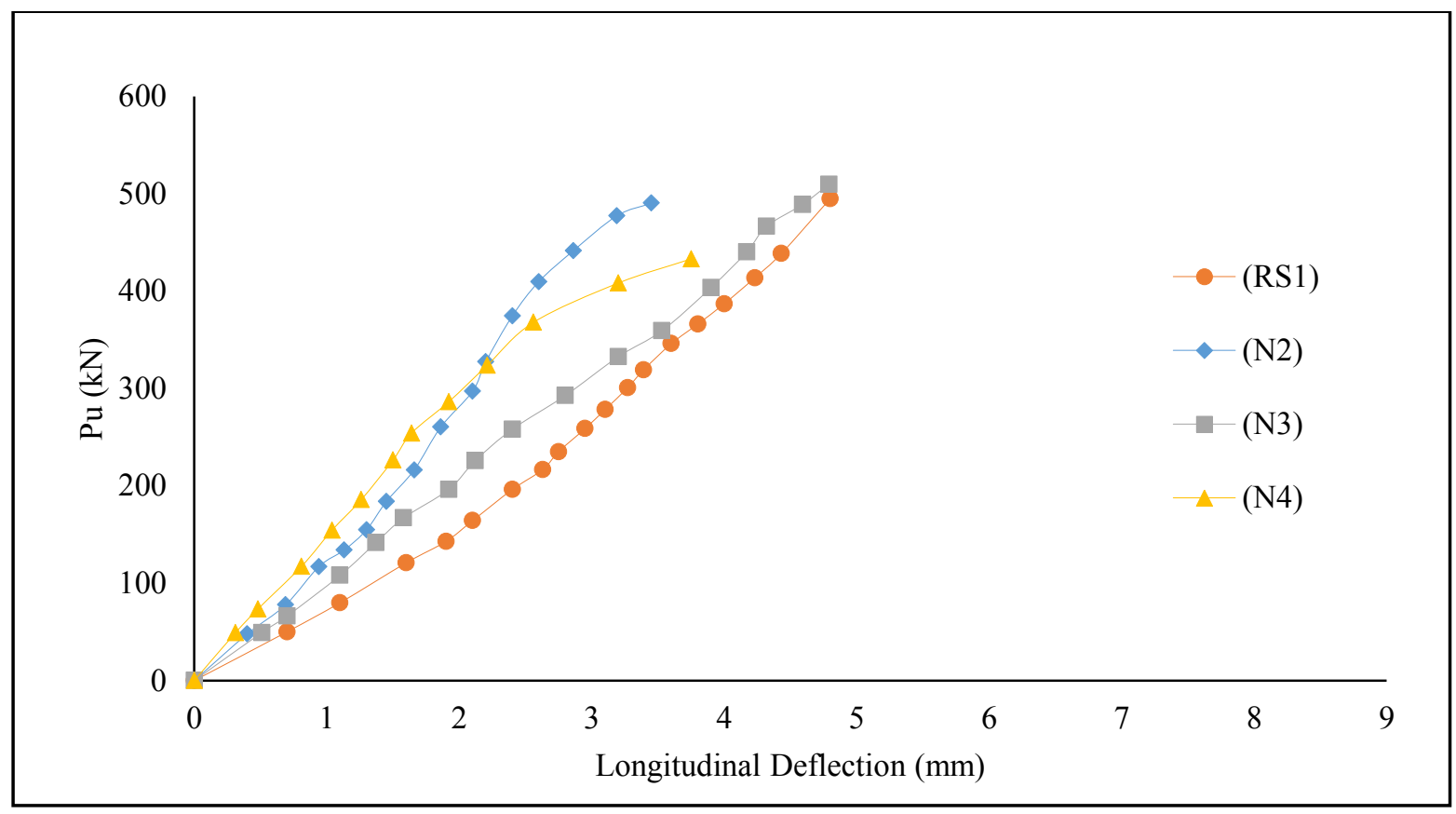

Fig. 3. Load - Longitudinal Deflection behaviour of Normal RC. column buried in clayey soil

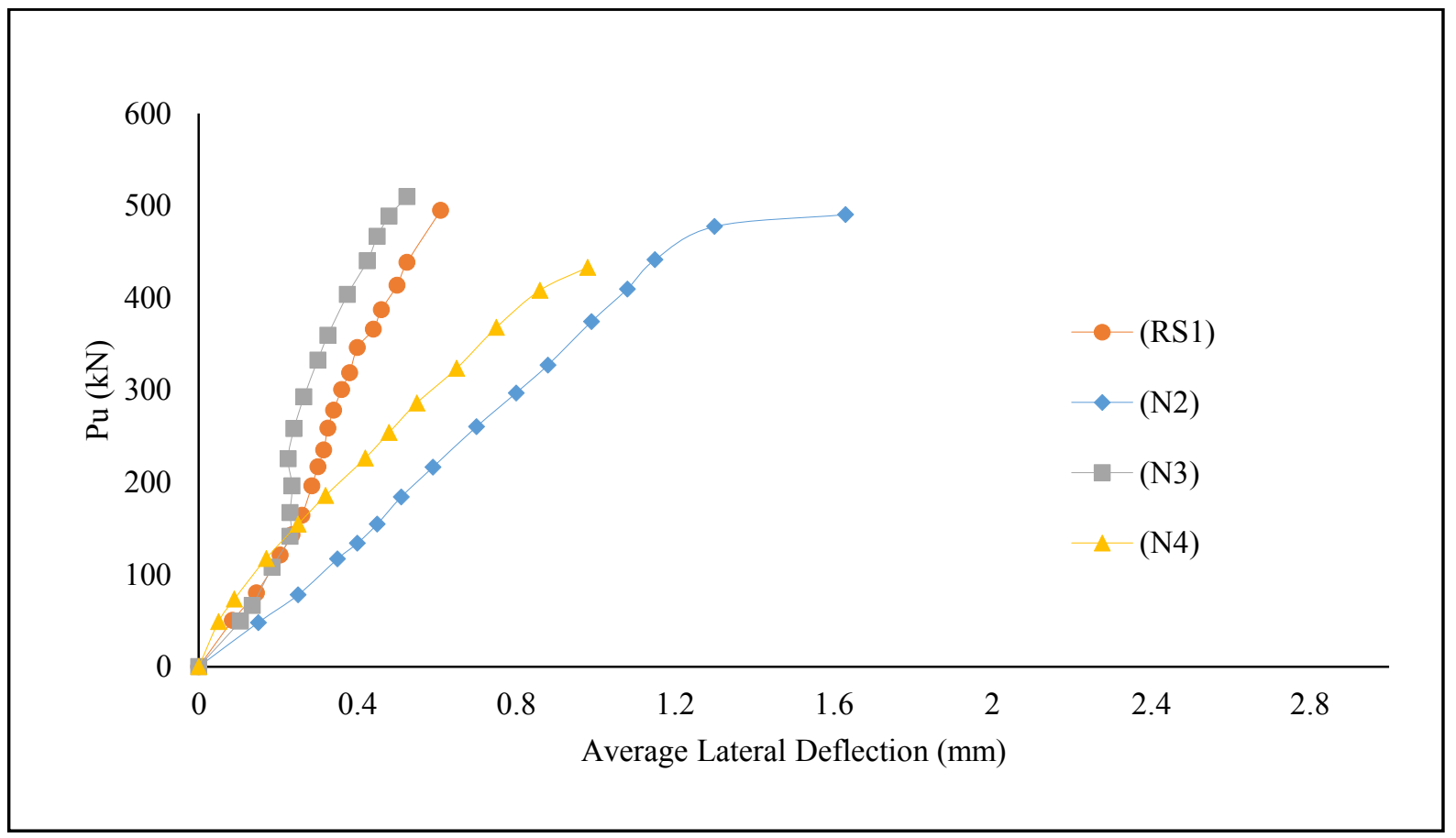

Fig. 4. Load - Lateral Deflection behaviour of Normal RC. column buried in clayey soil

After 60 days columns in the clayey soil, the normal mix remained conservative on its behavior and was not affected by sulfate salts during duration of 60 days. Visually there is no penetration of sulfate inside columns in this age. At the age of 150 days buried in the soil it notes an improvement in the strength of the concrete columns of the normal mix with a decrease in ductility, this may be due to the low proportion of sulfates in the soil at this age. The percentage of increase of normal mix strength was $2.98 \%$ with respect to reference column (RS1). By visual vision there is a penetration of sulfates in the normal column for depth $(3 \mathrm{~cm})$. At the age of 240 days of burial in the clayey soil, the concrete specimen's strength decreasing due to the high percentage of sulfates in the soil as in Table 4. The decreasing percentage of the strength in normal columns was $12.51 \%$ with respect to reference columns. Visually there is a penetration of sulfates for depth $(3.5 \mathrm{~cm})$. 


\subsection{Effect of Aggressive Solution of Sandy Soil}

The columns were buried for 60,150 , and 240 days in sandy soil to understand the effect of sulfate on reinforced concrete columns. The first visible crack in the normal Reinforced concrete columns group (Ns) was observed at top and bottom of these columns at applied load of $(142.92,158.4,111.24$, and 552.96) $\mathrm{kN}$ for columns (RS1, NS2, NS3, and NS4) respectively, NS4 failed suddenly without appearing cracks, with load sequence cracks grow and became wider. With continuous loading, the columns reached ultimate loads at $(495,439.2,529.56$, and 552.96) $\mathrm{kN}$ for columns (RS1, NS2, NS3, andNS4). See Figure 5.

Gradually failure occurred except column (NS4) which failed suddenly, it was observed for 60 days age of the column the compressive strength decreased and then it increased in the developed ages to reach its large strength at 240 days age. This means there was improvement in strength with $6.98 \%$ and $11.71 \%$ in 150 and 240 days ages respectively compared with reference strength, these happened because the concentration of sulfate decreased in sandy soil at 150 and 240 days as shown in Table 4. In the developed ages deflection decreased in longitudinal directions with time, due to which the columns became less tough and ductile because of the decrease in the area under the curve of load - deformation, so at last age it was found that for the same loading values, there is a decrease in the longitudinal deflection due to decrease in the toughness and ductility, these conclusions were covered by Figure 6. As seen in the Figure 7 the lateral deflection increases over time at the same load for example $(380 \mathrm{kN})$, these increments were the reflection the decrements in the longitudinal direction. From Table 5, it can be seen that, cracking load, and failure load of NS2, NS3 and NS4 with respect to RS1 are $(118,77$, and $386 \%)$, and (88, 106 and $111 \%$ ) respectively. The effect of the sulfate in sandy soil on the strength of columns during the time of buried is a possible reason for this increment in the lateral and longitudinal deflection.

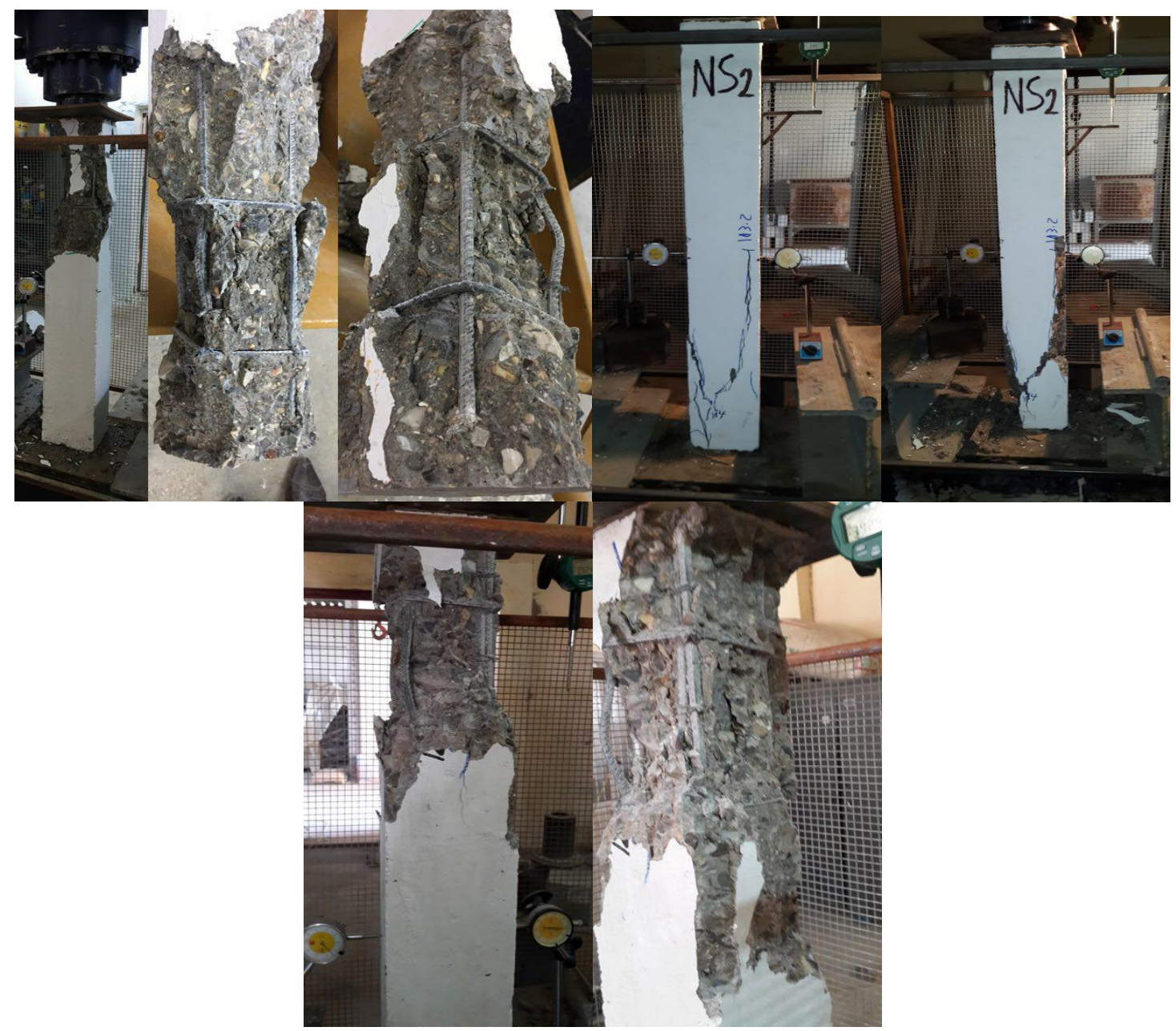

Fig. 5. Failure pattern for group (Ns) (* the load factored by 3.6) 


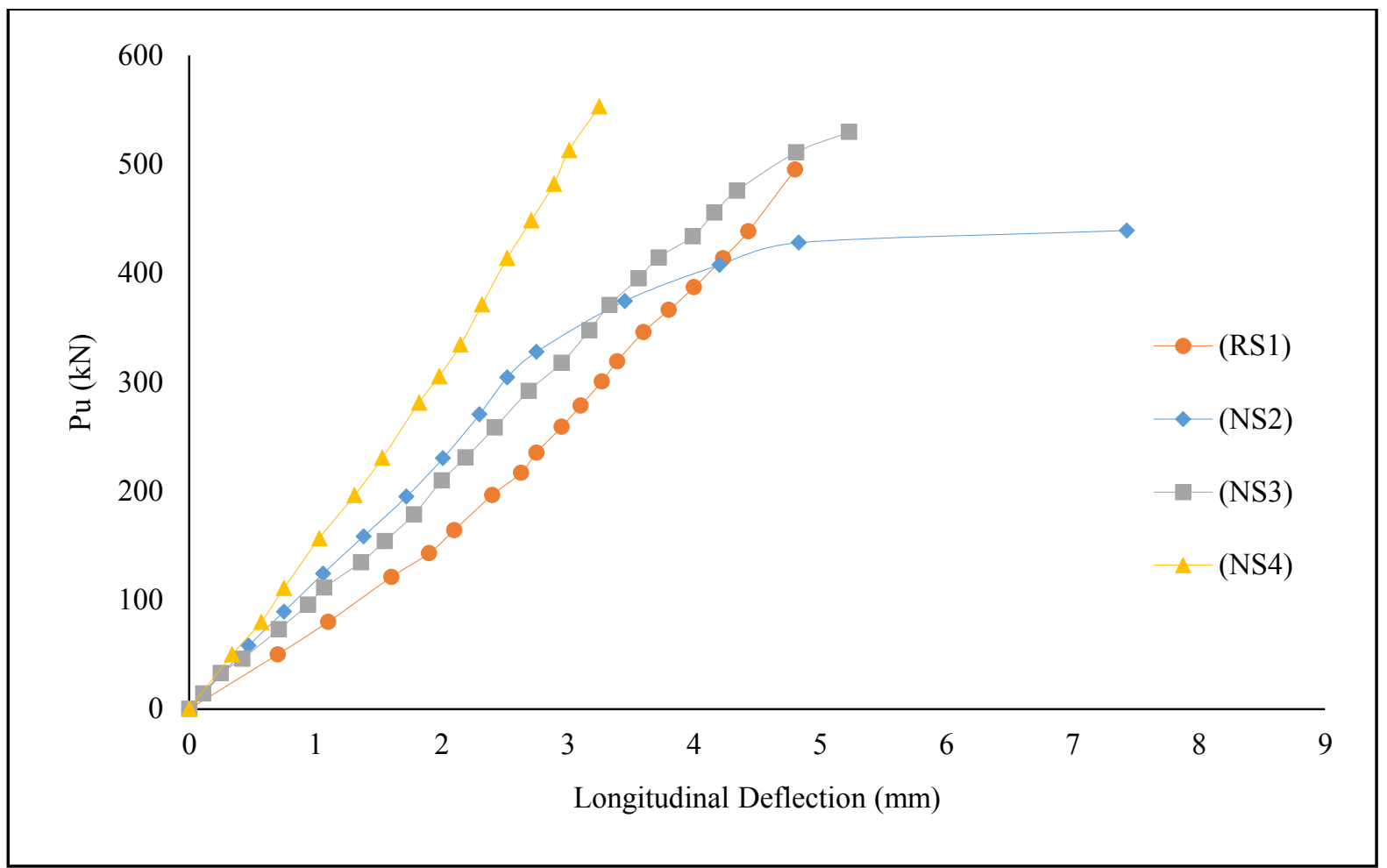

Fig. 6. Load - Longitudinal Deflection behaviour of Normal RC. column buried in sandy soil

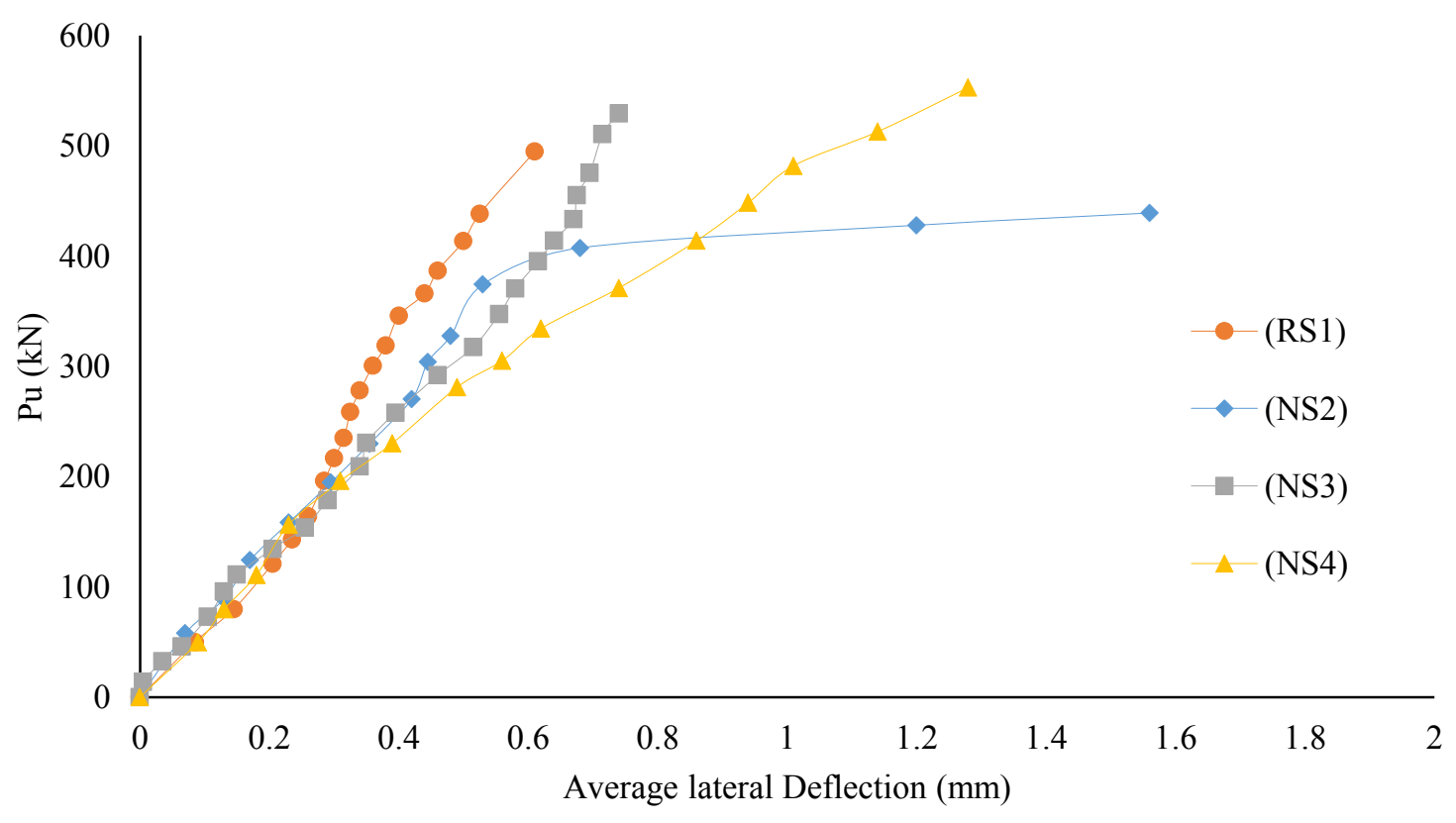

Fig. 7. Load - Lateral Deflection behaviour of Normal RC. column buried in sandy soil

At test age of 60 days high strength decreasing was recorded for normal reinforced concrete columns which reached to $11.27 \%$ compared to the reference strength, the failure was gradual in concrete columns. There is no penetration of sulfate inside columns in this test age. At 150 days the strength was enhanced, the increase became $6.98 \%$. From figures of load-deformation curves it can be seen the failure happened gradually. There was penetration for sulfate to the columns and its value was (4) $\mathrm{cm}$. Finally, at 240 days the increasing in strength was $11.71 \%$, the failure was suddenly, and the penetration was $(5 \mathrm{~cm})$. 
The columns in sandy soil were more ductile than the columns in clayey soil but, generally the behavior of

3.4 The Effect of Different Soils columns was relatively similar with a difference in the value of deformation and compressive strength recorded in each test, these are shown in Figure 8 to 10.

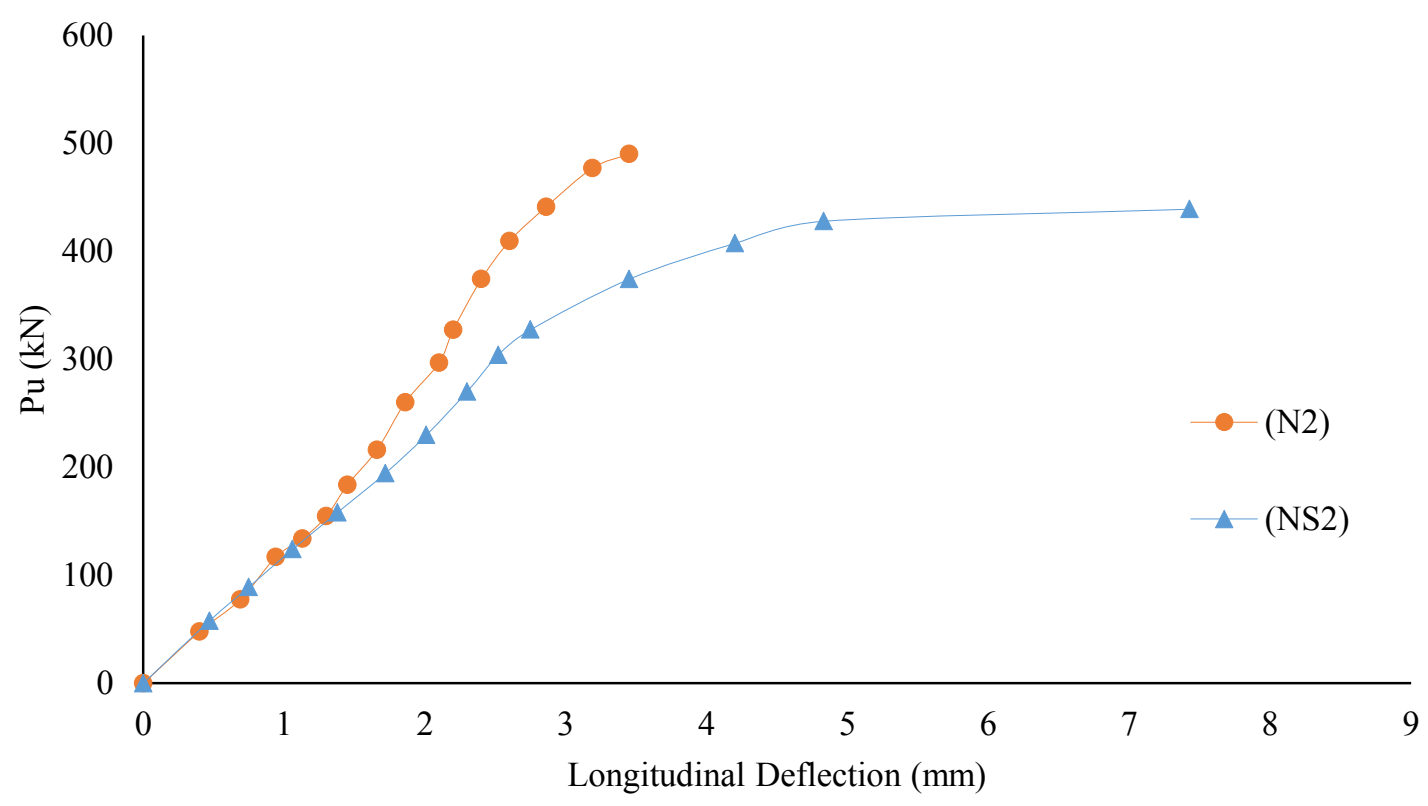

Fig. 8. Load - Longitudinal Deflection behavior of Normal RC. column buried in clayey and sandy soil for $\mathbf{6 0}$ days

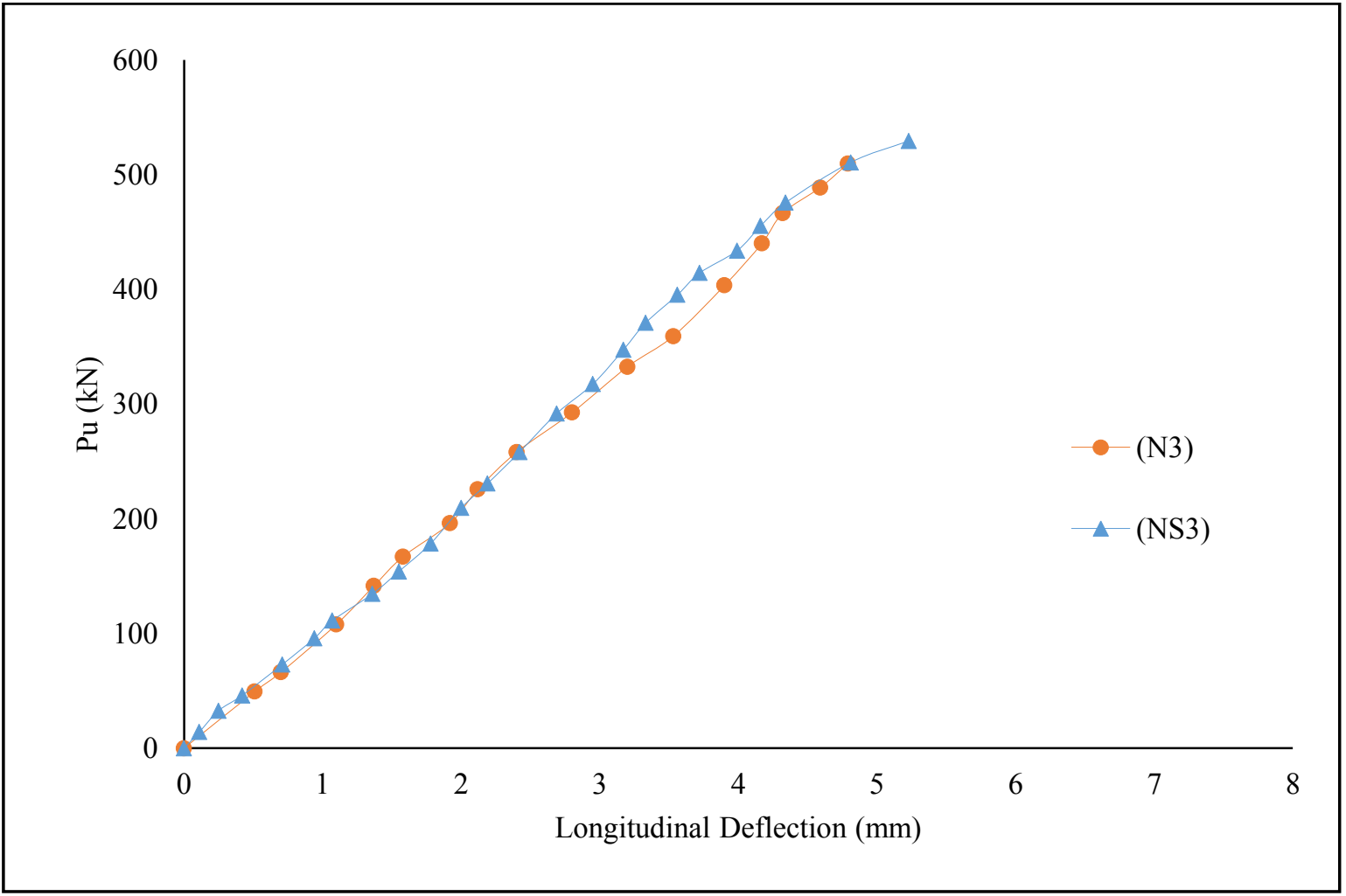

Fig. 9. Load - Longitudinal Deflection behavior of Normal RC. column buried in clayey and sandy soil for $\mathbf{1 5 0}$ days 


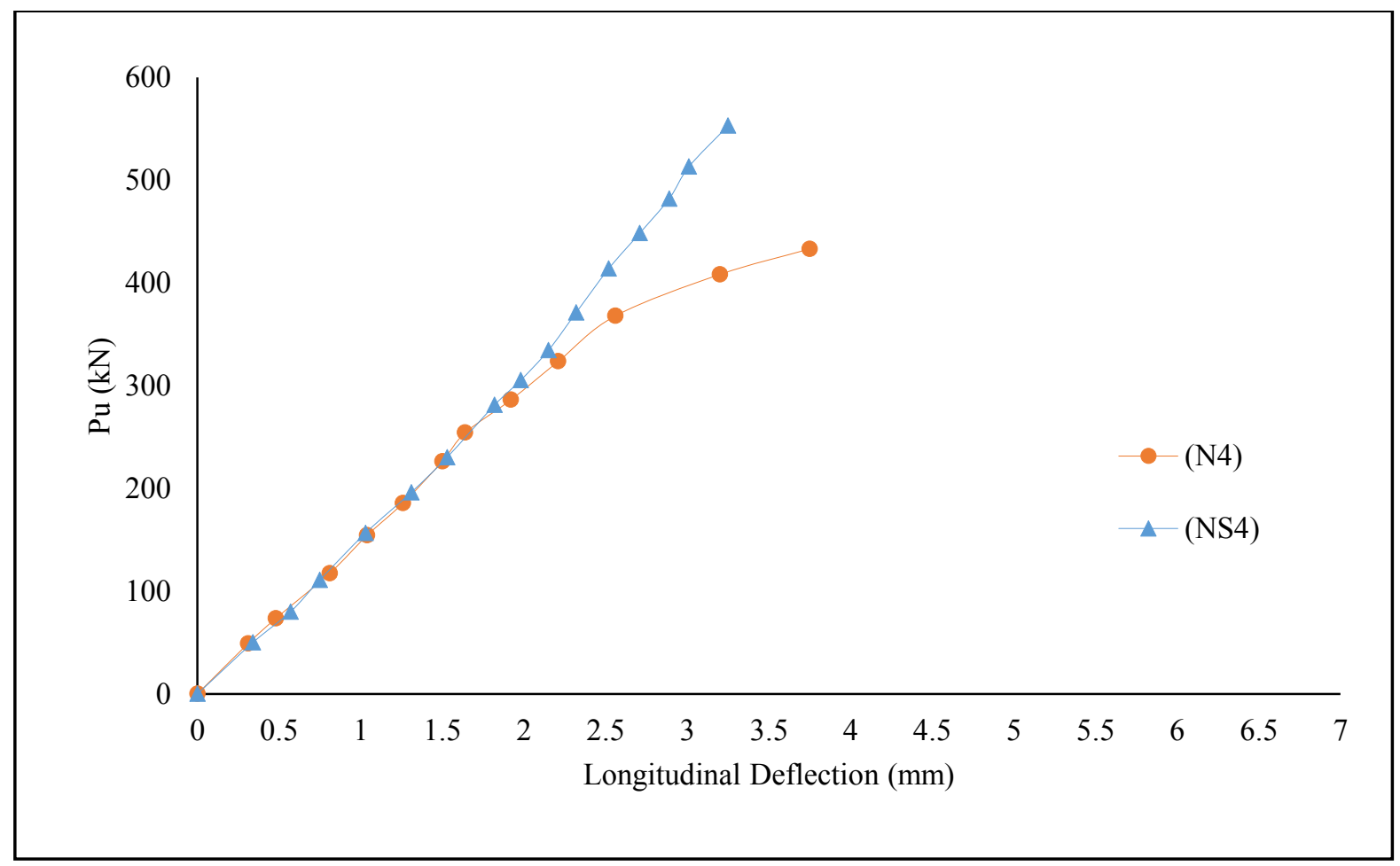

Fig. 10. Load - Longitudinal Deflection behaviour of Normal RC. column buried in clayey and sandy soil for 240 days

\section{Conclusions}

Based on the test results obtained from experimental program and the dissection of the results, the following conclusions can be drawn:

1. Ductility decreased with time, for models buried in clayey and sandy soils.

2. Strength of normal RC. columns decreased by $(12.51 \%)$ for age (240 days) and increased it by (2.98\%) for age (150 days), while it's not effected at age (60 days), all these changes were for columns buried in clayey soil, where the strength decreased by (11.27) \% for age (60) days while it enhanced in age $(150,240)$ days $(6.98,11.71) \%$ respectively, compared with reference columns, for columns buried in sandy soils.

3. The failure was gradual failure in normal RC. columns.

4. Decreasing the percentage of absorption ratio with time in normal concrete cubes, the highest ratio recorded at (240 days) age were $(5.09,9.83)$
$\%$ for sandy and clayey soils respectively, compared with reference cubes.

5. Decreasing the voids ratio with time in normal concrete cubes, the highest ratio recorded at (240 days) age were $(4.57,7.79) \%$ for sandy and clayey soils respectively, compared with reference cubes.

\section{References}

1. M.D. Cohen, B. Mather, Materials Journal 88, 1, 62-69 (1991)

2. K. Obla, C. Lobo, L. Lemay, Specifying concrete for durability. National Ready Mix Concrete Association, USA, (2006)

3. ASTM $/$ C150, Standard Specification for Portland Cement, in American Society for Testing and Materials, ASTM International West Conshohocken, $\mathrm{Pa}$ (1999)

4. Iraqi/Specification, No.5 Portland Cement (1984)

5. Iraqi/Specification, No. 45, Aggregates from Natural Sources for Concrete and Construction, Central Organization for Standardization andQuality Control COSQC (1984) 